\title{
瞋
}

Jenius: Journal of Education Policy and Elementary Education Issues

http://ejournal.iainsurakarta.ac.id/index.php/jenius/index

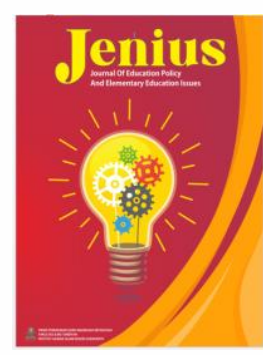

\section{Supervisi Akademik terhadap Kinerja Guru Sekolah Dasar pada Masa Pandemi Covid-19}

\author{
Niken Rosalina ${ }^{1}$, Ika Candra Sayekti², Rita Eryani² \\ 1,2 Pendidikan Profesi Guru, Universitas Muhammadiyah Surakarta, Indonesia
}

*Corresponding author: nikenrosalina21@gmail.com

\begin{tabular}{l} 
INFO ARTIKEL \\
\hline Riwayat Artikel \\
Diterima: 01-06-2021 \\
Disetujui: 15-06-2021 \\
Dipublikasikan: 19-07- \\
2021
\end{tabular}

\section{Kata kunci:}

Akademik; Kinerja Guru; Supervisi

\section{Keywords: \\ Academic; Teacher Performance; \\ Supervision}

\author{
ABSTRAK
}

Tujuan dalam penelitian ini adalah untuk mendeskripsikan perencanaan, pelaksanaan, evaluasi, dan tindak lanjut supervisi akademik yang dilakukan oleh Kepala Sekolah terhadap kinerja guru di SDN 2 Mojoreno selama pandemi pada bulan Februari 2021. Penelitian ini menggunakan metode penelitian kualitatif jenis studi kasus dengan teknik analisis data interaktif. Teknik pengumpulan data meliputi wawancara, observasi, dan dokumentasi. Hasil penelitian menunjukkan bahwa: 1) Perencanaan supervisi akademik: merumuskan tujuan, sasaran, ruang lingkup, teknik pelaksanaan supervisi selama pandemi dan instrumen supervisi; 2) Pelaksanaan supervisi akademik: dilakukan melalui observasi menggunakan platform zoom meeting dan wawancara menggunakan whatsapp group; 3) Evaluasi supervisi: beberapa guru masih terkendala penggunaan teknologi dalam menerapkan pembelajaran daring, kurang kreatifnya guru dalam memilih media pembelajaran, pelaksanaan pembelajaran belum sepenuhnya sesuai dengan rancangan pembelajaran; 4) Tindak lanjut supervisi akademik: pembinaan kinerja guru dalam mengelola pembelajaran virtual di Kelompok Kerja Guru (KKG) melalui zoom meeting atau whatsapp group. Hasil dari supervisi akademik digunakan sebagai pedoman refleksi dalam meningkatkan kinerja guru.

\section{ABSTRACT}

The purpose of this study was to describe the planning, implementation, evaluation, and follow-up of academic supervision carried out by the Principal on the performance of teachers at SDN 2 Mojoreno during the pandemic in February 2021. This study used a qualitative research method of case study type with data analysis techniques. interactive. Data collection techniques include interviews, observation, and documentation. The results showed that: 1) Academic supervision planning: formulating goals, objectives, scope, techniques for implementing supervision during a pandemic and supervision instruments; 2) Implementation of academic supervision: carried out through observations using the zoom meeting platform and interviews using whatsapp groups; 3) Evaluation of supervision: some teachers are still constrained by the use of technology in implementing online learning, teachers are less creative in choosing learning media, the implementation of learning is not fully in accordance with the learning design; 4) Follow-up academic supervision: teacher performance development in managing virtual learning in the Teacher Working Group (KKG) through zoom meetings or whatsapp groups. The results of academic supervision are used as a guide for reflection in improving teacher performance. 


\section{PENDAHULUAN}

Pada masa pandemi Coronavirus Disease (Covid-19), pelaksanaan pendidikan di Indonesia mengalami perubahan salah satunya sistem belajar dari rumah seperti yang tertuang dalam Surat Edaran Mendikbud Nomor 4 Tahun 2020 tentang pelaksanaan pendidikan dalam Covid-19. Belajar dari rumah tentu merupakan hal baru bagi semua pihak yang terlibat baik Kepala Sekolah, guru, siswa, serta orangtua wali murid. Harus ada kerjasama semua pihak agar dapat mencapai keberhasilan proses pembelajaran. Kondisi tersebut terjadi di SD Negeri 2 Mojoreno, Kecamatan Sidoharjo, Kabupaten Wonogiri, Jawa Tengah. Semua komponen sekolah harus beradaptasi dengan perubahan yang ada terutama guru sebagai pengelola pembelajaran di dalam kelas. Kinerja guru sangat menentukan keberhasilan suatu pembelajaran dalam menghadapi pembelajaran jarak jauh selama pandemi.

Kinerja guru merupakan hasil yang telah dicapai oleh guru dalam pembelajaran sesuai dengan ketentuan nasional (Hardono \& Yusuf, 2017). Untuk meningkatkan kinerja guru terutama pada masa pandemi perlu dilaksanakan supervisi akademik oleh Kepala Sekolah. Melalui kegiatan supervisi, Kepala Sekolah dan guru dapat mengetahui kelemahan serta kelebihan proses pembelajaran yang telah dilaksanakan sehingga mampu melakukan perbaikan. Prestasi siswa ditentukan oleh kompetensi yang dimiliki oleh guru. Sebagaimana kompetensi guru meliputi kompetensi pedagogik, kompetensi kepribadian, kompetensi sosial, dan kompetensi profesional (Chauhan \& Sharma, 2015). Oleh karena itu, guru diharapkan memiliki keempat kompetensi tersebut.

Kompetensi guru dapat diamati dari kemampuan guru dalam sistem pengelolaan pembelajaran di dalam kelas. Pengelolaan pembelajaran perlu dilaksanakan untuk memudahkan pengelola mencapai tujuan pendidikan sesuai yang tertuang dalam peraturan pemerintah atau undang-undang pendidikan yang berlaku (Rozalena \& Kristiawan, 2017). Salah satu sistem pengelolaan pembelajaran adalah kegiatan belajar mengajar. Sebelum melaksanakan kegiatan belajar mengajar, guru harus menciptakan suasana kelas yang nyaman. Pada masa pembelajaran daring seperti saat ini, suasana kelas tentu berbeda. Siswa dan guru tidak bertemu secara langsung di ruang kelas melainkan di ruang virtual seperti zoom meeting, google meet, danilain-lain. Namun, tidak semua guru melaksanakan pembelajaran virtual. Masih banyak guru yang kurang bisa memanfaatkan platform yang sudah ada sehingga proses pembelajaran hanya dilaksanakan dengan memberikan materi dan tugas melalui Whatsapp group. Guru hanya terpaku dalam pemberian soal-soal evaluasi tanpa memperhatikan kondisi 
lingkungan belajar dan siswa walaupun hanya melalui ruang virtual, sebab hasil belajar siswa tidak akan maksimal jika lingkungan tidak kondusif.

Purbasari (2015) menyatakan bahwa kinerja guru dapat meningkat karena dipengaruhi oleh supervisi akademik yang dilaksanakan oleh kapala sekolah. Kemudian berdasarkan hasil pengujian diperoleh kesimpulan bahwa di SMK Negeri 1 Bungoro Kabupaten Pangkep supervisi akademik yang dilaksanakan oleh Kepala Sekolah memiliki pengaruh yang cukup besar terhadap kinerja guru yaitu sebesar 10,5\% (Amanda \& Saggaf, 2017). Selanjutnya berdasarkan penelitian yang dilakukan oleh Nata \& Kaleka (2020) diperoleh kesimpulan bahwa kegiatan supervisi yang dilaksanakan oleh Kepala Sekolah mampu meningkatkan kinerja guru. Hal tersebut dapat diketahui dari siklus I terdapat 70\% guru tuntas dan meningkat pesat pada siklus II yaitu terdapat $100 \%$ guru tuntas. Terakhir, berdasarkan hasil supervisi akademik yang telah dilaksanakan oleh Kepala Sekolah di SD Negeri 16 Gelumbang diperoleh kesimpulan bahwa terdapat $40 \%$ guru dalam kategori sangat baik dan $60 \%$ guru dalam kategori cukup baik. Dengan demikian dapat dikemukakan bahwa hasil supervisi akademik dapat meningkatkan kinerja guru di SD Negeri 16 Gelumbang (Zulfakar \& Fitria, 2020). Hal ini menunjukkan bahwa kegiatan supervisi akademik yang dilakukan oleh Kepala Sekolah sangat penting karena berpengaruh terhadap peningkatan kompetensi guru khususnya kompetensi pedagogik.

Berdasarkan hasil observasi awal di SDN 2 Mojoreno menunjukkan kegiatan supervisi di masa pandemi sudah dilaksanakan oleh Kepala Sekolah. Namun, supervisi yang dilakukan selama masa pandemi belum maksimal. Hal tersebut berdasar hasil wawancara dengan Kepala Sekolah yang menyatakan bahwa guru belum maksimal dalam melakukan pengelolaan kelas virtual. Selain itu, kegiatan tindak lanjut juga belum dilaksanakan secara rutin baik oleh guru maupun Kepala Sekolah sendiri. Berdasar permasalahan di atas, maka peneliti perlu untuk menganalisis peranan supervisi dalam perencanaan, pelaksanaan, evaluasi, dan tindak lanjut supervisi akademik Kepala Sekolah untuk meningkatkan kinerja guru SDN 2 Mojoreno pada masa pandemi. Tindak lanjut dari hasil analisis supervisi ini digunakan untuk melakukan perbaikan kedepannya terhadap kinerja guru.

\section{METODE}

Penelitian ini merupakan penelitian kualitatif dengan menerapkan desain penelitian studi kasus yang dianalisis secara deskriptif. Penelitian dilakukan di SDN 2 Mojoreno pada bulan Februari 2021. Sumber data dalam penelitian ini dibedakan menjadi dua, yaitu sumber data primer dan sumber data sekunder. Sumber data primer diperoleh dari hasil wawancara dan 
observasi dengan subjek penelitian yaitu Kepala Sekolah, guru, dan siswa mengenai supervisi akademik Kepala Sekolah untuk meningkatkan kinerja guru pada masa pandemi. Sumber data sekunder meliputi dokumentasi yang berkaitan dengan data sekolah seperti profil sekolah, profil guru, daftar peserta didik, dan instrumen supervisi akademik. Penelitian ini menggunakan teknik analisis data interaktif dengan reduksi data, penyajian data, dan penarikan kesimpulan, sesuai dengan pendapat Miles dan Huberman (Sari \& Ekawati, 2013). Sedangkan keabsahan data yang digunakan adalah teknik triangulasi meliputi triangulasi sumber serta triangulasi teknik. Triangulasi sumber dilaksanakan melalui cara pengecekan data yang diperoleh melalui beberapa sumber yaitu Kepala Sekolah, guru, dan siswa. Sedangkan triangulasi teknik berupa data yang diperoleh dari wawancara, observasi, dan dokumentasi.

\section{HASIL DAN PEMBAHASAN}

\section{Perencanaan Supervisi Akademik di SDN 2 Mojoreno pada Masa Pandemi}

Penelitian ini menunjukkan bahwa tujuan supervisi akademik di masa pandemi yaitu untuk meningkatkan kinerja guru serta memberikan pembinaan mengenai pembelajaran daring di masa pandemi. Sesuai wawancara dengan Kepala Sekolah diketahui bahwa tujuan dari diadakannya supervisi akademik oleh Kepala Sekolah di SDN 2 Mojoreno adalah untuk meningkatkan kinerja guru dalam pembelajaran daring. Jawaban tersebut diperkuat oleh guru kelas III yang mengungkapkan bahwa tujuan supervisi akademik di SDN 2 Mojoreno adalah untuk memberikan pembinaan terhadap kinerja guru pada masa pandemi. Hal ini sejalan dengan pernyataan Susanto (2016) juga menyatakan bahwa tujuan supervisi akademik adalah untuk meningkatkan kualitas pembelajaran yang dijalankan oleh guru. Sedangkan Prasojo (2011) menyebutkan tujuan supervisi akademik antara lain membantu guru dalam mengembangkan kompetensinya antara lain dengan kegiatan Kelompok Kerja Guru (KKG) dan Penelitian Tindakan Kelas (PTK). Supervisi akademik cukup penting karena mampu memberikan bantuan, bimbingan, serta layanan kepada guru dalam melaksanakan proses pembelajaran (Suradi, 2018).

Sasaran utama dari supervisi akademik adalah guru kelas yaitu kinerja guru dalam pengelolaan proses pembelajaran daring di dalam kelas terutama pada masa pandemi melalui kelas virtual. Hal tersebut sesuai dengan pendapat Prasojo (2011) yang mengemukakan bahwa inti supervisi akademik yang dilaksanakan kepala sekolah adalah untuk membina guru agar mutu pembelajaran dapat meningkat. Sedangkan ruang lingkup supervisi akademik di SDN 2 Mojoreno ada 3 yaitu perencanaan pembelajaran, pelaksanaan pembelajaran, dan penilaian 
pembelajaran. Hal tersebut sesuai dengan pendapat Prasojo (2011) menjelaskan bahwa ruang lingkup supervisi akademik meliputi beberapa hal diantaranya yaitu persiapan, pelaksanaan, dan penilaian pembelajaran oleh guru.

Teknik supervisi akademik yang diterapkan di SDN 2 Mojoreno pada masa pandemi yaitu teknik individu dan kelompok. Sesuai yang diungkapkan Kepala Sekolah bahwa supervisi akademik di SDN 2 Mojoreno dilaksanakan dengan observasi kegiatan pembelajaran sesuai dengan RPP yang telah dipersiapkan. Sebelum pandemi, teknik individu dengan cara kunjungan kelas. Namun sekarang dengan wawancara dan observasi. Observasi dilaksanakan dalam pembelajaran virtual melalui zoom. Namun, jika guru tidak melaksanakan pembelajaran observasi dilaksanakan pada whatsapp group dengan mengamati aktivitas percakapan guru dan siswa. Hal tersebut sesuai dengan pendapat Susanto (2016) bahwa teknik perorangan dalam kegiatan supervisi dilakukan dengan cara mengadakan kunjungan kelas, observasi, serta pembimbingan guru mengenai cara mempelajari pribadi siswa, pelaksana kurikulum dan pembelajaran. Sedangkan teknik kelompok berupa kegiatan diskusi yang dilaksanakan secara virtual melalui googlemeet. Menurut Hanief (2016) teknik supervisi kelompok adalah sebuah cara yang dilakukan dalam kegiatan supervisi ditujukan untuk lebih dari satu orang. Sebelum kegiatan supervisi dilaksanakan, Kepala Sekolah menyiapkan segala sesuatu yang diperlukan pada proses supervisi yang disebut instrumen supervisi. Instrumen supervisi antara lain lembar observasi proses pembelajaran sesuai dengan RPP yang sudah dipersiapkan. Instrumen supervisi digunakan untuk menilai kinerja guru mulai dari perencanaan, pelaksanaan, dan penilaian pembelajaran. Di dalam menyusun program supervisi Kepala Sekolah mengacu kepada hasil evaluasi dan analisis pelaksanaan supervisi akademis tahun sebelumnya (Rohmawati, 2019). Dengan demikian, hasil temuan dapat digunakan oleh Kepala Sekolah dan guru sebagai gambaran bahwa perencanaan supervisi akademik meliputi penetapan tujuan, sasaran, ruang lingkup, teknik, dan instrumen supervisi akademik.

\section{Pelaksanaan Supervisi Akademik di SDN 2 Mojoreno pada Masa Pandemi}

a. Tahap pertemuan awal

Pada tahap pertemuan awal, Kepala Sekolah berkomunikasi dengan guru kelas terkait perangkat pembelajaran yang telah dipersiapkan mulai dari program tahunan, program semester, silabus, serta RPP. Perangkat pembelajaran tentu harus disesuaikan dengan kondisi daring. Hal tersebut sesuai dengan yang diungkapkan oleh Guru Kelas III bahwa RPP yang dipersiapkan adalah RPP daring. Jika sebelum pandemi guru menyiapkan perangkat 
pembelajaran dalam bentuk printout, untuk saat ini guru cukup mengunggah seluruh perangkat pembelajaran ke one drive microsoft office 365. Hal tersebut diperkuat oleh pendapat Kepala Sekolah yang menyatakan bahwa seluruh sekolah di Kabupaten Wonogiri diwajibkan untuk memiliki akun microsoft ioffice 365. Tidak hanya sekolah, setiap guru juga harus mempunyai akun tersebut yang sinkron dengan akun sekolah. Hal tersebut memudahkan Kepala Sekolah untuk mengecek kelengkapan perangkat pembelajaran guru kelas.

Kepala Sekolah juga mengajukan beberapa pertanyaan terkait persiapan maupun proses pembelajaran yang telah dilaksanakan di masa pandemi. Berdasarkan hasil wawancara dengan guru kelas III diperoleh informasi bahwa dalam pembelajaran daring tentu banyak kendala yang dihadapi salah satunya kemampuan dan kemauan guru dalam mengelola kelas virtual karena masih ada beberapa guru yang tidak melaksanakan pembelajaran virtual namun hanya memberikan materi berupa link youtube dan tugas melalui whatsapp group. Hal tersebut diperkuat oleh pendapat siswa kelas III yang menyebutkan bahwa pembelajaran virtual melalui zoom meeting tidak rutin dilaksanakan. Biasanya jika ada materi yang susah seperti matematika baru dilaksanakan pembelajaran melalui zoom. Selain itu, jaringan internet juga menjadi salah satu kendala pembelajaran daring. Dengan demikian proses pembelajaran daring di SDN 2 Mojoreno belum maksimal dilaksanakan. Siswa belum mendapatkan pengalaman belajar yang menyenangkan. Sedangkan Trinova (2012) menjelaskan bahwa untuk memperoleh situasi pembelajaran yang menyenangkan dan menggembirakan siswa harus diarahkan memiliki motivasi yang tinggi. Pembelajaran dikatakan menyenangkan apabila seluruh siswa dapat memusatkan perhatian secara penuh terhadap materi pembelajaran yang disampaikan oleh guru. Temuan diatas dapat digunakan untuk memperbaiki praktik persiapan supervisi salah satunya yaitu sebelum melakukan observasi, Kepala Sekolah mengajukan beberapa pertanyaan terkait perangkat pembelajaran yang akan digunakan oleh guru.

b. Tahap observasi

Tahap observasi dilaksanakan dengan menggunakan instrumen observasi. Instrumen observasi terdiri dari observasi tahap perencanaan, pelaksanaan, dan penilaian pembelajaran. Pada tahap perencanaan, Kepala Sekolah mengamati perangkat pembelajaran yang telah disusun oleh guru kelas. Perangkat pembelajaran yang disusun harus sesuai dengan kondisi daring dan kebutuhan siswa. Beberapa perangkat pembelajaran yang diperlukan dalam proses pembelajaran antara lain RPP, Silabus, LKS, buku dan alat evaluasi (Tanjung \& Nababan, 2018). Salah satu hal yang menjadi fokus pengamatan yaitu penyusunan RPP daring. Di SDN 2 Mojoreno komponen RPP daring tetap lengkap sesuai dengan Permendikbud Nomer 22 tahun 
2016. Jadi tidak menerapkan RPP 1 lembar.

Pada tahap pelaksanaan, Kepala Sekolah mengamati proses pembelajaran sesuai dengan RPP yang telah disusun. Dalam kondisi daring, Kepala Sekolah tidak dapat masuk ke ruang kelas. Oleh karena itu pengamatan dilaksanakan pada saat pembelajaran virtual melalui zoom meeting dan pada saat pemberian materi serta tugas melalui whatsapp group. Jadi Kepala Sekolah sebagai supervisor bergabung pada whatsapp group setiap kelas. Proses pembelajaran belum sepenuhnya sesuai dengan rencana yang telah disusun. Media pembelajaran serta bahan ajar yang diberikan kepada siswa juga kurang bervariatif. Masih ada beberapa guru yang hanya mengambil video melalui youtube. Sedangkan Umar (2017) mengungkapkan bahwa dalam proses pembelajaran memerlukan alat perantara antara guru dan siswa yang dinamakan media pembelajaran. Dengan menggunakan media pembelajaran diharapkan komunkasi dan interaksi dalam proses pembelajaran lebih aktif dan efektif. Oleh karena itu, perlu bagi guru untuk mengembangkan media pembelajaran. Pada penutup pembelajaran, guru kelas memberikan soal-soal sebagai kegiatan evaluasi terhadap siswa.

Penilaian pembelajaran dilaksanakan dengan form evaluasi yang diberikan melalui link google form serta pemberian LKPD pada link google drive. Evaluasi pembelajaran secara online berbasis website mampu menjadi sarana yang mudah untuk guru dan siswa dalam melaksanakan penilaian (Fuady, 2017). Evaluasi pembelajaran adalah proses untuk menilai hasil belajar siswa selama proses pembelajaran. Selain itu juga melalui buku yang dikumpulkan setiap satu minggu sekali. Untuk penilaian sikap dapat diketahui dari kebiasaan siswa dalam masuk ke zoom meeting tepat waktu, mengumpulkan tugas tepat waktu, dan kegiatan lain yang dapat diamati walaupun tidak bertemu langsung di kelas. Dengan demikian, penilaian yang mencakup tiga ranah yaitu pengetahuan, sikap, dan keterampilan tetap dapat dilaksanakan walaupun dalam kondisi daring kurang maksimal. Hasil temuan diatas dapat digunakan sebagai bahan pertimbangan Kepala Sekolah sebagai supervisor dalam menjalankan tugas dalam mengamati baik persiapan, pelaksanaan, maupun evaluasi pembelajaran di masa pandemi.

\section{Evaluasi Supervisi Akademik di SDN 2 Mojoreno pada Masa Pandemi}

Evaluasi supervisi akademik di SDN 2 Mojoreno dilaksanakan dengan tujuan yaitu mengetahui kelebihan serta kelemahan supervisi akademik yang telah dilaksanakan sehingga mampu melaksanakan perbaikan untuk pelaksanaan supervisi mendatang. Sesuai dengan pendapat Yazdani (2015) yang menyatakan bahwa evaluasi yang paling sulit dilaksanakan adalah evaluasi kegiatan guru. Evaluasi supervisi akademik dilaksanakan setelah pelaksanaan supervisi. Evaluasi dilaksanakan oleh Kepala Sekolah beserta guru yang bersangkutan. Sesuai 
dengan pendapat Paramudita (2019) yang menyatakan bahwa evaluasi supervisi akademik dilaksanakan untuk mengetahui kekurangan dan kelebihan proses supervisi serta untuk mengetahui apakah akan diadakan tindak lanjut untuk mengembangkan kemampuan guru.

Dalam evaluasi supervisi akademik di SDN 2 Mojoreno tahun pelajaran 2020/2021 diketahui bahwa pelaksanaan supervisi sudah berjalan dengan baik. Kinerja guru juga sudah baik namun belum maksimal. Hal tersebut dikarenakan pada masa pandemi pembelajaran dilaksanakan secara daring, oleh sebab itu guru harus mampu menyesuaikan perubahan tersebut. Tidak sedikit guru yang masih memiliki beberapa kendala salah satunya kurangnya pengetahuan teknologi. Sedangkan kinerja guru mencakup perencanaan, pengelolaan, dan penilaian hasil belajar siswa (Suhayati, 2013). Tidak hanya pada guru, kendala juga dihadapi oleh siswa. Banyak siswa yang belum memiliki smarphone sebagai sarana utama pembelajaran daring sehingga hanya menggunakan smartphone orangtua. Saat orangtua bekerja, tentu anak akan terkendala mengikuti pembelajaran virtual. Penilaian sikap juga sulit dilaksanakan jika tidak bertatap muka secara langsung dengan siswa. Sedangkan menurut Tiara \& Sari (2019) selain pengembangan pengetahuan, pengembangan sikap siswa juga sangat penting untuk ditanamkan di sekolah karena setiap siswa pasti memiliki sikap yang berbeda. Dari kegiatan pembelajaran, diharapkan dapat mengembangkan penilaian terhadap sikap siswa. Oleh karena itu, pembelajaran virtual belum dapat dilaksanakan secara maksimal. Hasil temuan dapat digunakan sebagai bahan pertimbangan apakah diperlukan tindak lanjut berupa pengembangan kompetensi guru setelah mengetahui kelebihan serta kelemahan pada proses evaluasi.

\section{Tindak Lanjut Supervisi Akademik di SDN 2 Mojoreno pada Masa Pandemi}

Menurut Prasojo (2011) kegiatan tindak lanjut supervisi akademik perlu dilaksanakan guna memanfaatkan hasil supervisi untuk perbaikan sehingga dapat meningkatkan profesionalisme guru. Tindak lanjut supervisi di SDN 2 Mojoreno berupa pembinaan terhadap kinerja guru dalam mengelola pembelajaran di kelas virtual yaitu melalui zoom meeting atau whatsapp group. Pembinaan kinerja guru dengan memberikan motivasi guru untuk mengikuti kegiatan KKG yang dilaksanakan oleh setiap Gugus per Kecamatan. Sesuai pendapat Al Rasyid (2017) yang menyatakan bahwa KKG mampu menjadi tempat untuk meningkatkan kemampuan profesional guru terutama dalam mengelola kegiatan pembelajaran di dalam kelas. Pada masa pandemi seperti sekarang, KKG dilaksanakan secara virtual melalui google meet. Walaupun dilaksanakan secara virtual, namun ilmu yang disampaikan oleh pemateri tetap dapat diterima oleh peserta. Setelah mengikuti KKG, peserta juga akan mendapatkan sertifikat. 
Sesuai dengan pendapat Paramudita (2019) yang menyatakan bahwa fokus tindak lanjut kegiatan supervisi yaitu mengenai pemantapan instrumen perangkat pembelajaran sehingga diperlukan pembinaan untuk guru baik secara langsung maupun tidak langsung sehingga dapat melakukan proses perbaikan dari hasil analisis.

Tindak lanjut supervisi tidak hanya dilaksanakan oleh guru, namun juga Kepala Sekolah sebagai supervisor. Suwartini (2017) menjelaskan bahwa Kepala Sekolah harus memahami manajemen supervisi dan kepemimpinan mengingat Kepala Sekolah merupakan pemegang kekuasaan utama di sekolah. Kepala Sekolah sebagai supervisor memiliki tanggungjawab dalam pelaksanaan supervisi akademik salah satunya yaitu bertugas menyiapkan nstrumen supervisi serta imelakukan perbaikan dan pemantapan instrumen supervisi. Kegiatan tersebut dapat dilakukan dengan cara diskusi kelompok oleh para Kepala Sekolah sebagai supervisor tentang instrumen supervisi akademik yang digunakan. Supervisi dapat berjalan dengan baik apabila supervisor mampu menunjukkan sikap yang bersahabat, mampu mendengarkan lawan bicara dengan baik, berusaha meningkatkan partisipasi aktif, ikut memberikan ide mengenai teknik analisis masalah, mampu memberi saran, serta membuat penilaian (Waluya, 2013). Hasil temuan diatas dapat digunakan sebagai solusi bagi guru dalam mengembangkan kompetensi dengan cara mengikuti pelatihan, seminar, atau kegiatan lainnya.

\section{KESIMPULAN DAN SARAN}

\section{Simpulan}

Perencanaan supervisi akademik Kepala Sekolah dalam meningkatkan kinerja guru SDN 2 Mojoreno pada masa pandemi terdiri dari merumuskan tujuan supervisi akademik, sasaran supervisi akademik, ruang lingkup supervisi akademik, teknik supervisi akademik dengan menentukan pelaksanaan supervisi selama pandemi, dan instrumen supervisi akademik. Pelaksanaan supervisi akademik Kepala Sekolah melalui pemeriksaan perangkat pembelajaran oleh Kepala Sekolah dan observasi terhadap kinerja guru dalam kelas virtual melalui zoom meeting dan whatsapp group menggunakan instrumen observasi supervisi akademik. Evaluasi supervisi akademik Kepala Sekolah bertujuan untuk meningkatkan kinerja guru dan mengetahui kekurangan serta kelebihan kegiatan supervisi akademik. Hasil evaluasi yaitu beberapa guru masih belum bisa mengoperasikan teknologi dalam mendukung pembelajaran daring, proses pembelajaran belum sepenuhnya sesuai dengan rancangan pembelajaran, media pembelajaran yang digunakan guru belum bervariatif. Tindak lanjut supervisi akademik Kepala Sekolah dilakukan melalui kegiatan KKG secara virtual untuk melakukan pembinaan terhadap 
guru. Hasil dari supervisi akademik dijadikan sebagai pedoman refleksi bagi kepala sekolah dan guru dalam meningkatkan kinerja guru.

\section{DAFTAR RUJUKAN}

Al Rasyid, H. (2017). Fungsi kelompok kerja guru (KKG) bagi pengembangan keprofesionalan guru sekolah dasar. Sekolah Dasar: Kajian Teori Dan Praktik Pendidikan, 24(2), 143-150.

Amanda, M. O., Salam, R., \& Saggaf, S. (2017). Pengaruh supervisi kepala sekolah terhadap kinerja guru di SMK Negeri 1 Bungoro kabupaten Pangkep. Prosiding Seminar Nasional Himpunan Sarjana Ilmu-Ilmu Sosial, 2, 149-154.

Chauhan, A., \& Sharma, P. (2015). Teacher education and total quality management (TQM). The International Journal of Indian Psychology, 2(2), 80-85.

Fuady, M. J. (2017). Pengembangan aplikasi evaluasi pembelajaran online untuk pendidikan jarak jauh. Tekno, 26(2, 148-154.

Hanief, M. (2016). Menggagas teknik supervisi klinik sebagai upaya peningkatan mutu pembelajaran. Vicratina: Jurnal Pendidikan Islam, 1(2).

Hardono, H., Haryono, H., \& Yusuf, A. (2017). Kepemimpinan kepala sekolah, supervisi akademik, dan motivasi kerja dalam meningkatkan kinerja guru. Educational Management, 6(1), 26-33.

Nata, N., \& Kaleka, M. B. U. (2020). Meningkatkan kinerja guru melalui supervisi akademik kepala sekolah dengan pendekatan individual di SMPN 7 Nangapanda. OPTIKA: Jurnal Pendidikan Fisika, 4(1), 1-8. doi: 10.37478/optika.v4i1.282.

Paramudita, A. (2019). Teknik supervisi akademik di sekolah islam. Madrasa, 2(1), 1-6.

Prasojo, L. D. (2011). Supervisi pendidikan. Yogyakarta: Gava Media.

Purbasari, M. (2015). Pengaruh supervisi akademik terhadap kinerja mengajar guru di sekolah dasar. Journal of Elementary Education, 4(1), 46-52.

Rohmawati, M. (2019). Supervisi akademik kepala sekolah. Manajer Pendidikan, 13(2), 207211.

Rozalena, R., \& Kristiawan, M. (2017). Pengelolaan pembelajaran paud dalam mengembangkan potensi anak usia dini. JMKSP (Jurnal Manajemen, Kepemimpinan, Dan Supervisi Pendidikan), 2(1), 76-86. doi: 10.31851/jmksp.v2i1.1155.

Sari, D. M., Surantoro, S., \& Ekawati, E. Y. (2013). Analisis kesalahan dalam menyelesaikan soal materi termodinamika pada siswa SMA. Jurnal Materi Dan Pembelajaran Fisika, 3(1), 1-7.

Suhayati, I. Y. (2013). Supervisi akademik kepala sekolah, budaya sekolah dan kinerja mengajar guru. Jurnal Administrasi Pendidikan, 17(1), 86-95. doi: 10.17509/jap.v17i1.6435.

Suradi, A. (2018). Supervisi akademik kepala sekolah terhadap kinerja guru pendidikan agama islam di sekolah dasar negeri 79 kota Bengkulu. Jurnal Pendidikan Dasar Islam, 5(1), 13- 
29.

Susanto, A. (2016). Konsep, strategi, dan implementasi manajemen peningkatan kinerja guru. Jakarta: Prenadamedia Group.

Suwartini, E. A. (2017). Supervisi akademik kepala sekolah, profesionalisme guru dan mutu pendidikan. Jurnal Administrasi Pendidikan, 24(2), 62-70. doi: 10.17509/jap.v24i2.8294.

Tanjung, H. S., \& Nababan, S. A. (2018). Pengembangan perangkat pembelajaran matematika berorientasi model pembelajaran berbasis masalah (PBM) untuk meningkatkan kemampuan berpikir kritis siswa SMA Se-Kuala Nagan Raya Aceh. Genta Mulia: Jurnal Ilmiah Pendidikan, 9(2), 56-70.

Tiara, S. K., \& Sari, E. Y. (2019). Analisis teknik penilaian sikap sosial siswa dalam penerapan kurikulum 2013 di SDN 1 Watulimo. EduHumanioral Jurnal Pendidikan Dasar Kampus Cibiru, 11(1), 21-30. doi: 10.17509/eh.v11i1.11905.

Trinova, Z. (2012). Hakikat belajar dan bermain menyenangkan bagi peserta didik. Al-Ta Lim Journal, 19(3), 209-215. doi: 10.15548/jt.v19i3.55.

Umar, U. (2017). Media pendidikan: Peran dan fungsinya dalam pembelajaran. Tarbawiyah: Jurnal Ilmiah Pendidikan, 11(01), 131-144.

Waluya, J. (2013). Supervisi pendidikan pada sekolah dasar. Pedagogik (Jurnal Pendidikan Sekolah Dasar), 1(1), 34-42.

Yazdani, F. (2015). Investigation about teachers' and managers' view about annual evaluation system of teachers' performance in iran. Creative Education, 6(14), 1523. doi: $10.4236 /$ ce.2015.614152

Zulfakar, Z., Lian, B., \& Fitria, H. (2020). Implementasi supervisi akademik dalam meningkatkan kinerja guru. JMKSP (Jurnal Manajemen, Kepemimpinan, Dan Supervisi Pendidikan), 5(2), 230-244. doi: 10.31851/jmksp.v5i2.3833. 